\title{
Efektivitas Sistem Pengendalian Internal pada Pengelolaan Persediaan Barang Habis Pakai (Alat Tulis Kantor) di Dinas Pertanian dan Pangan Kota Magelang
}

\author{
Wiwit Isna Ardiyanti ${ }^{1}$, Nuwun Priyono ${ }^{2}$ \\ ${ }^{1}$ Akuntansi, Fakultas Ekonomi, Universitas Tidar \\ e-mail : wiwitardiyanti6@gmail.com \\ ${ }^{2}$ Akuntansi, Fakultas Ekonomi, Universitas Tidar \\ e-mail : nuwunpriyono@untidar.ac.id
}

\begin{abstract}
This study aims to determine the effectiveness of the internal control system in the management of consumable supplies at the Office of Agriculture and Food in Magelang City. Management of goods is said to be effective if in carrying out and managing these activities it does not cause unwanted problems and these activities are in accordance with applicable regulations so that they can achieve company goals. In the management of goods, there are several processes, the process of managing these goods consists of the process of receiving, storing, maintaining, distributing or releasing, and controlling processes. This study uses qualitative research using descriptive methods. This research was conducted at the Office of Agriculture and Food Office of Magelang City in the General Affairs and Personnel Section and data was obtained through interviews and literature review with the warehouse manager of the Office of Agriculture and Food, Magelang City. In this study it was concluded that the internal control system was running well and effectively, because it had implemented the elements of internal control.
\end{abstract}

Keywords: Effectiveness, Internal Control, Consumables

\begin{abstract}
Abstrak
Penelitian ini bertujuan untuk mengetahui efektivitas sistem pengendalian internal pada pengelolaan persediaan barang habis pakai di Kantor Dinas Pertanian dan Pangan Kota Magelang. Pengelolaan barang dikatakan efektif apabila dalam menyelengarakan dan mengurus kegiatan tersebut tidak menimbulkan masalah yang tidak dikehendaki dan kegiatan tersebut telah sesuai dengan peraturan yang berlaku sehingga bisa mencapai tujuan perusahaan. Dalam pengelolaan barang ada beberapa proses,proses
\end{abstract}


pengelolaan barang tersebut terdiri dari proses penerimaan, penyimpanan, pemeliharaan, pendistribusian atau pengeluaran, dan proses pengendalian. Penelitian ini menggunakan penelitian kualitatif dengan menggunakan metode deskriptif. Penelitian ini dilaksanakan pada kantor Dinas Pertanian dan Pangan Kota Magelang di Bagian Umum dan Kepegawaian dan data diperoleh melalui wawancara dan kajian pustaka dengan Bagian pengelola gudang kantor Dinas Pertanian dan Pangan Kota Magelang. Dalam penelitian ini disimpulkan bahwa sistem pengendalian internal sudah berjalan dengan baik dan efektif, karena telah menerapkan unsur-unsur pengendalian internal.

Kata kunci : Efektvitas, Pendendalian Internal, Barang Habis Pakai

\section{PENDAHILUAN}

Peraturan Pemerintah Nomor 27 Tahun 2014 menyebutkan bahwa Barang Milik Daerah (BMD) adalah semua barang yang dibeli atau diperoleh atas beban Anggaran Pendapatan dan Belanja Daerah atau berasal dari perolehan lainnya yang sah. Menurut Peraturan Pemerintah Nomor 71 Tahun 2010 disebutkan bahwa aset adalah sumber daya ekonomi yang dikuasai dan dimiliki oleh pemerintah sebagai akibat dari peristiwa masa lalu dan dari mana manfaat ekonomi dan sosial dimasa depan diharapkan dapat diperoleh, baik oleh pemerintah maupun masyarakat, serta dapat diukur dalam satuan uang, sosial, maupun politik.

Adanya pedoman tentang pengelolaan Barang Milik Daerah (BMD) diharapkan perusahaan atau instansi dapat memanfaatkan barang yang diperoleh dengan seoptimal mungkin dan tidak adanya penggunaan barang secara berlebihan. Pengelolaan Barang Milik Daerah merupakan suatu kegiatan yang harus dilakukan dengan baik dan berpedoman kepada peraturan perundang-undangan sehingga dapat memberikan gambaran tentang Barang Milik Daerah yang mampu memenuhi kebutuhan barang di Lingkungan suatu perusahaan atau instansi terutama di kantor Dinas Pertanian dan Pangan Kota Magelang. 
Kegiatan pengelolaan barang setiap perusahaan maupun instansi baik swasta ataupun pemerintah harus memenuhi setiap proses pengelolaan barang yang terdiri dari proses penerimaan, penyimpanan, pemeliharaan, pendistribusian atau pengeluaran serta proses pengendalian atau pengawasan untuk mencapai tujuan yang efektif dan efisien bagi perusahaan maupun instansi baik pemerintah maupun swasta. Pada umumnya perusahaan yang akan melakukan pencapaian tujuan akan berusaha untuk meningkatkan efektivitas dan efisiensi kerjanya dengan menerapkan strategi-strategi tertentu yang telah ditetapkan. Salah satu strategi yang dapat dilakukan oleh sebuah instansi adalah menerapkan pengendalian internal terhadap pengelolaan barang persediaan.

Menurut Baramuli (2015) Persediaan memiliki peran yang penting sebagai sumber daya ekonomi fisik yang diadakan dan dipelihara untuk menunjang proses. Persediaan adalah salah satu aset yang rawan terhadap penyelewengan dan sangat rentan terjadi kerusakan, maupun pencurian maka perusahaan sangat perlu melakukan evaluasi efektivitas pengendalian internal untuk membantu tujuan perusahaan dan mengurangi risiko.

Faktor kunci pengelolaan organisasi yang efektif adalah pengendalian internal yang baik, karena pengendalian internal melibatkan penataan tanggung jawab dalam organisasi (Tandri et al., 2015). Tujuan pengendalian internal atas persediaan adalah untuk memastikan bahwa di dalam persediaan tersebut tidak terjadi penyalahgunaan sehingga bisa diamankan juga dilaporkan secara benar dalam laporan keuangan. Committee of Sponsoring Organization of The Treadway Commission (COSO) dikutip dalam Marshall dan Steinbart (2006:230) ada 5 komponen sistem pengendalian internal yang efektif dan saling terkait yaitu:

1. Lingkungan pengendalian (control environment)

2. Penilaian resiko (risk assestment)

3. Aktivitas pengendalian (control activities)

Wiwit Isna Ardiyanti - Efektivitas Sistem Pengendalian Internal pada Pengelolaan Persediaan Barang Habis Pakai (Alat Tulis Kantor) di Dinas Pertanian dan Pangan Kota Page | 44 Magelang 
4. Informasi dan komunikasi (information and communication)

5. Pengawasan (monitoring)

Komponen-komponen ini diperlukan untuk mencapai suatu sistem pengendalian internal yang efektif dan efisien serta berguna dalam melindungi aktiva perusahaan terhadap penyalahgunaan persediaan seperti kecurangan, pemborosan dan pencurian yang dilakukan oleh pihak internal maupun eksternal perusahaan. Sistem pengendalian internal yang memadai dalam pengelolaan persedian barang harus memenuhi beberapa hal yaitu harus adanya pemisahan fungsi, mulai dari proses perencanaan, penerimaan, pengeluaran, dan pencatatan dengan persetujuan dari pihak yang berwenang. Tujuan dari penelitian ini yaitu untuk mengetahui Efektivitas Sistem Pengendalian Internal pada Persediaan Barang Habis Pakai (ATK) di kantor Dinas Pertaniasn dan Pangan Kota Magelang

\section{METODE PENELITIAN}

Penelitian ini menggunakan metode kualitatif. Menurut Moleong (2005), penelitian kualitatif adalah penelitian yang bermaksud untuk memahami fenomena tentang apa yang dialami oleh subjek penelitian dengan cara deskripsi dalam bentuk kata-kata dan bahasa, pada suatu konteks khusus yang alamiah dan dengan memanfaatkan berbagai metode alamiah.

Penelitian ini termasuk jenis penelitian deskriptif kualitatif yaitu penelitian yang menggambarkan atau melukiskan objek penelitian berdasarkan fakta yang tampak sebagaimana adanya. (Nawawi dan Martini 1996: 73). Penelitian ini dilaksanakan melalui wawancara dan observasi pada kantor Dinas Pertanian dan Pangan Kota Magelang.

Penelitian ini berlokasi di kantor Dinas Pertanian dan Pangan Kota Magelang yang beralamat lenglap Jl. Kartini No. 3, Cacaban, Kec. Magelang TengaKota 
Magelang, Jawa Tengah. Penelitian dilaksanakan pada 13 Januari 2020 -13 Februari 2020.

Metode analisis yang digunakan adalah metode pendekatan kualitatif, yaitu analisis deskriptif. Metode analisis deskriptif kualitatif adalah metode untuk menganalisis, menggambarkan, dan meringkas berbagai kondisi, situasi dari berbagai data yang dikumpulkan berupa hasil wawacara atau pengamatan mengnai masalah yang diteliti yang terjadi di lapangan. (Wirata, 2006)

\section{HASIL DAN PEMBAHASAN}

Efektivitas sistem pengendalian internal dalam menjalankan pengelolaan pergudangan yang digunakan pada kantor Dinas Pertanian dan Pangan Kota Magelang di Sub Bagian Umum dan Kepegawaian terdiri dari :

1. Proses Penerimaan

Proses penerimaan adalah proses penyerahan dan penerimaan logistik dan peralatan di gudang. Dalam proses penerimaan dan penyerahan ini dilakukan :

a. Pendataan jumlah dan mutu logistik dan peralatan harus sesuai dengan ketentuan.

b. Pencatatan administarif sebagai dokumen yang dapat dipertanggung jawabkan oleh petugas yang bersangkutan.

Pada kantor Dinas Pertanian dan Pangan Kota Magelang proses penerimaan dapat dilihat dari kegiatan awal yaitu melakukan pendataan sesuai dengan prosedur dengan menyertakan dokumen yang menyertai jenis,jumlah dan harga barang. Kemudian dilakukan pengecekan oleh pengelola gudang sesuai dengan data pesanan yang selanjutnya barang tersebut disusun didalam gudang. 


\section{Proses Penyimpanan}

Proses penyimpanan merupakan proses kegiatan penyimpanan peralatan di gudang dengan cara menempatkan peralatan yang diterima dengan :

a. Penempatan sesuai dengan jenis

b. Aman dari pencurian

c. Aman dari gangguan fisik

d. Penataan sesuai dengan standar pergudangan.

Kantor Dinas Pertanian dan Pangan Kota Magelang, setelah dari proses penerimaan kemudian dilakukan proses penyimpanan oleh pengelola gudang yang disusun pada lemari besi khusus Alat Tulis Kantor sesuai dengan jenisnya masing-masing.

\section{Proses Pemeliharaan}

Proses pemeliharaan merupakan kegiatan perwawatan peralatan agar kondisi tetap terjamin dan siap pakai untuk digunakan dalam kegiatan operasional,melalui prinsip yaitu :

a. Ringkas, rapih, resik (bersih), rawat dan rajin.

b. Barang disusun di atas lemari secara rapiih,teratur dan sesuai dengan ketentuan.

Proses pemeliharaan pada kantor Dinas Pertanian dan Pangan Kota Magelang dilakukan oleh pengelola gudang dengan menyusun barang sesuai dengan jenisnya dan melakukan pengecekan barang setelah melakukan kegiatan penerimaan dan pendistribusian. Pemeliharaan juga dilakukan pada gudang penyimpanan dengan mengunci gudang setelah digunakan dan setelah selesai jam kantor.

4. Proses Pendistribusian

Proses Pendistribusian merupakan kegiatan pengeluaran dan penyaluran peralatan dari gudang untuk diserahkan kepada yang berhak, melalui suatu proses serah terima yang dapat dipertanggung jawabkan, disertai dengan 
bukti serah terima. Proses pendistribusian akan tercipta secara efektif jika terjadi kerjasama yang erat antara satuan-satuan kerja pengguna Alat Tulis Kantor tertentu dengan para petugas pengelolaan gudang Alat Tulis Kantor itu sendiri, yaitu :

a. Kebutuhan yang jelas. Pengguna Alat Tulis Kantor menyampaikan kebutuhannya dengan jelas.

b. Kecekatan petugas. Pengelola gudang dapat memproses permintaan yang diterimanya dan menyampaikan kepada bagian-bagian kantor secara cekatan.

Pada kantor Dinas Pertanian dan Pangan Kota Magelang proses pendistribusian barang sebelum di keluarkan dari gudang,pengelola gudang pertama kali mencatat permintaan karyawan. Selanjutnya,pengelola gudang mengambil barang tersebut di gudang dan mencatat pengeluaran barang pada sistem komputer hal ini dilakukan sebagai acuan untuk digunakan pada tahun-tahun berikutnya. Proses pendistribusian pada kantor Dinas Pertanian dan Pangan Kota Magelang ini menerapkan prosedur barang yang pertama masuk akan keluar terlebih dahulu dari gudang.

5. Proses Pengendalian

Proses pengendalian merupakan proses pengawasan atas pergerakan masuk keluarnya peralatan dari dan ke gudang agar persediaan dan penempatan dapat diketahui secara cepat,tepat dan akurat. Pada kantor Dinas Pertanian dan Pangan Kota Magelang proses pengendalian dilakukan dengan cara mengunci gudang pada saat selesai jam kantor dan jika pengelola gudang tidak berada ditempat maka gudang dititipkan kepada salah satu karyawan dengan menyertakan kartu bon barang.

Penerapan Sistem Pengendalian Internal menurut COSO, Seperti yang dikemukakan oleh Cynthia Amanda,dkk (2014) pada Persediaan barang dagang pada grand hardware manado,meliputi :

Wiwit Isna Ardiyanti - Efektivitas Sistem Pengendalian Internal pada Pengelolaan Persediaan Barang Habis Pakai (Alat Tulis Kantor) di Dinas Pertanian dan Pangan Kota Page | 48 
a. Lingkungan Pengendalian

Kantor Dinas Pertanian dan Pangan Kota Magelang menjunjung tinggi integritas dan nilai-nilai etika. Hal ini dibuktikan dengan adanya pernyataan kebijakan dan aturan pelaksanaan yang telah dibuat oleh instansi. Aturan-aturan tersebut bisa menjadi dasar atau patokan bagi pegawai dan karyawan agar selalu bersikap baik dan sesuai dengan aturan serta menjunjung tinggi profesionalitas serta kesetiaan pada perusahaan.

Dokumen-dokumen yang terkait dalam proses penerimaan dan pengeluaran barang diarsipkan secara sistematis dengan dan terkomputerisasi dengan baik. Setiap laporan yang dihasilkan menunjukkan informasi yang benar yang berhubungan dengan peersediaan barang habis pakai. Struktur Organisasi pada kantor Dinas Pertanian dan Pangan Kota Magelang telah berjalan dengan baik dan secara fungsional menunjukkan garis-garis wewenang dan tanggung jawab yang jelas dalam aktivitas operasional instansi.

b. Penilaian Risiko

Penilian Risiko pada pengelolaan persediaan barang habis pakai yang dilakukan oleh pengelola gudang pada kantor Dinas Pertanian dan Pangan Kota Magelang telah dilkukan dengan cukup baik. Pengelola gudang telah mengenali risiko-risiko yang ada,dan membentuk aktivitas-aktivitas pengendalian untuk menghadapi tersebut. Penentuan risiko pada persediaan barang habis pakai pada kantor Dinas Pertanian dan Pangan Kota Magelang dilakukan atas pertimbangan persediaan barang habis pakai yang mudah sobek ataupun barang yang mudah berkarat,dengan meletakkan pada rak yang paling atas dan dengan mengadakan pengecekan setiap hari. 
c. Informasi dan Komunikasi

Informasi dan komunikasi pada kantor Dinas Pertanian dan Pangan Kota Magelang sudah dilaksanakan dengan cukup baik. Sistem Informasi dilakukan dari proses penerimaan, penyimpanan, pemeliharaan, pendistribusian atau pengeluaran, dan pengendalian. Semua kegiatan pengelolaan persediaan barang habis pakai pada kantor Dinas Pertanian dan Pangan Kota Magelang dilakukan pencatatan secara terkomputerisasi sehingga bisa lebih efesien saat melakukan pemeriksaan.

d. Aktivitas Pengendalian

Kebijakan aktivitas pengendalian pada kantor Dinas Pertanian dan Pangan Kota Magelang,yaitu dengan pemisahan tugas dalam pengelolaan persediaan barang habis pakai,adanya otorisasi yang tepat yang telah dilakukan oleh kantor Dinas Pertanian dan Pangan Kota Magelang atas setiap proses penerimaan,pendistrubusian atau pengeluaran barang dari gudang dengan pembubuhan tandatangan oleh pihak berwenang untuk menyetujui setiap terjadinya proses pengelolaan barang dan dokumendokumen yang terkait dengan proses penerimaan,penyimpanan dan pendistribusian persediaan barang habis pakai pada kantor Dinas Pertanian dan Pangan Kota Magelang sudah cukup baik,yaitu surat bukti serah terima dan surat permintaan barang.

Kantor Dinas Pertanian dan Pangan Kota Magelang cukup efektif dalam melkukan pengawasan fisik terhadap persediaan barang habis pakai dengan diletakkannya kamera CCTV di setiap sudut instansi termasuk gudang,sehingga bisa meminimalisir adanya tindakan penyelewengan.

e. Pengawasan

Pengawasan terhadap persediaan barang habis pakai pada kantor Dinas Pertanian dan Pangan Kota Magelang dilakukan oleh pihak internal instansi. Prosedur pengawasan juga melibatkan beberapa fungsi yang 
berada di kantor Dinas Pertanian dan Pangan Kota Magelang. Sehingga pengawasan sudah dilaksanakan denga cukup baik. Pengawasan terhadap persediaan barang habis pakai yang dilakukan oleh kantor Dinas Pertanian dan Pangan Kota Magelang dimulai dari gudang sebagai tempat penyimpanan dan pusat keluar masuknya persediaan.

Hasil tersebut didapatkan melalui wawancara dengan Bapak Juwari selaku pengelola gudang pada kantor Dinas Pertanian dan Pangan Kota Magelang Tanggal 5 Februari 2020.

\section{KESIMPULAN}

Pengelolaan persediaan barang habis pakai yang dilakukan di kantor Dinas Pertanian dan Pangan Kota Magelang terdiri dari Proses penerimaan, penyimpanan, pemeliharaan, pendistribusian atau pengeluaran, dan proses pengendalian. Hal ini telah sesuai dengan Peraturan Badan Nasional Penanggulangan Bencana Nomor 6 Tahun 2009 tentang Pedoman Pergudangan.

Pengendalian intern terhadap pengelolaan persediaan barang habis pakai pada kantor Dinas Pertanian berjalan cukup efektif. Lingkungan pengendalian kantor Dinas Pertanian dan Pangan sudah cukup baik, struktur oragnisasi yang ada telah berjalan secara fungsional. Penilaian risiko oleh instansi sudah cukup baik,pengantisipasian yang dilakukan untuk setiap risiko yang mungkin. Aktivitas pengendalian akan prosedur penerimaan,pendistrubusian atau pengeluaran barang dari gudang sudah memadai dengan dilakukan pengarsipan secara sistematis dan terkomputerisasi. Kegiatan pengawasan sudah cukup baik karena diawasi oleh penanggung jawab gudang dengan pengamanan CCTV.

\section{DAFTAR PUSTAKA}

Akmal. 2007. Pemeriksaan Intern (Internal Audit) . Jakarta : Gramedia, hlm. 25. Amanda, Cynthia, Jullie J Sondakh, Dan Steven J Tangkuman. “Analisis Efektivitas Sistem Pengendalian Internal Atas Persediaan Barang Dagang Pada Grand 
Hardware Manado",Jurnal Riset Ekonomi, Manajemen, Bisnis Dan Akuntansi,03 (2015),766-776.

Amerieska, S., Setiati, F., \& Mulyono, I. "Analisis Faktor Tentang Efektivitas Pengelolaan Barang Milik Daerah (Studi Pada Badan Pengelolaan Keuangan Dan Aset Daerah Kabupaten Malang)",Jurnal Ilmiah Bisnis Dan Ekonomi Asia,12 (2018),53-65.

Baramuli, Friska, dan Sifrid s Pangemanan. "Analisis Sistem Informasi Akuntansi

Persediaan Pada Yamaha Bima Motor Toli-Toli”,Jurnal Emba,03 (2015),52-26.

Hangin Petronela, Elfreda A Lau, Dan Heriyanto. “Analisis Pengelolaan Persediaan

Pada Pt. Daun Buah Kaltim Di Samarinda",Universitas 17 Agustus 1945

Samarinda

Heizer, Jay dan Barry Render.2005.Manajemen Operasi, Edisi 7. Jakarta: Salemba Empat.

Herwinanti, Anastasya, Zahroh Z A, Dan Devi Farah Azizah. "Analisis Sistem Dan Prosedur Persediaan Bahan Habis Pakai Dalam Upaya Meningkatkan Pengendalian Intern (Studi Kasus Pada Pt. Wiranas Laundry And Dry Clean Malang)",Jurnal Administrasi Bisnis,12 (2014).

Hery. 2013. Dasar Akuntansi. Jakarta : Media Kom, hlm. 159.

J.Moleong, Lexy. 2005. Metodologi Penelitian Kualitatif. Bandung: Remaja Rosdakarya, hlm. 6.

Mardiasmo. 2008. Akuntansi Sektor Publik. Yogyakarta : Andi,hlm.134

Marshall, Romney B. dan Paul John Steinbart. 2006. Accounting Information System.

9. Jakarta : Salemba Empat,hlm. 230.

Morasa, J., Maksurat, A., \& Elim, I. "Penerapan Sistem Pengendalian Intern Untuk

Persediaan Barang Dagangan Pada Cv. Multi Media Persada Manado",Jurnal Emba

Mulyadi. 2001. Sistem Akuntansi. Jakarta : Salemba Empat, hlm. 553.

Nawawi, H danMartini,M. 1966. Penelitian Terapan. Yogyakarta : Universitas Gajah Mada Press,hlm. 73.

Peraturan Badan Nasional Penanggulangan Bencana Nomor 6 Tahun 2009 tentang Pedoman Pergudangan.

Peraturan Pemerintah Nomor 27 Tahun 2014 tentang Pengelolaan Barang Milik

Daerah.

Sulasmi. "Pengaruh Pengendalian Internal Pada Persediaan Terhadap Efektivitas Perusahaan Pada PT. Swakarya Indah Busana",Universitas Maritim Raja Ali Haji

Susanto, Azhar. 2008. Sistem Informasi Akuntansi. Bandung : Lingga Jaya,hlm. 95. 
Tandri, Marchel, Jullie J Sondakh, dan Harjianto Sabijono. "Efektivitas Penerapan Sistem Pengendalian Intern Terhadap Penerimaan Dan Pengeluaran Kas Di Rsu Pancaran Kasih Penerimaan Dan Pengeluaran Kas Di Rsu Pancaran Kasih",Jurnal EMBA,03 (2015),208-2018.

Wawancara dengan pengelola gudang Dinas Pertanian dan Pangan Kota Magelang.

Winarni, Sri. "Analisis Pengendalian Intern Atas Persediaan Sparepart Pada PT.Astra Internatioanl Tbk Honda Cabang Muara Enim",Jurnal Ilmiah,06 (2013), 1151-1161.

Wirata,I Made. Metode Penelitian Sosial Ekonomi . Yogyakarta: Andi Offset , (2006) , hal.155 